\title{
Velamentous Vessel
}

National Cancer Institute

\section{Source}

National Cancer Institute. Velamentous Vessel. NCI Thesaurus. Code C117351.

A fetal blood vessel in the placental membranes that extends from the cord insertion to the chorionic plate. 